\title{
Trends and patterns of medical and health research at Moi University, Kenya, between 2002 and 2014: an informetrics study
}

\author{
Daniel Chebutuk Rotich ${ }^{1}$ and Omwoyo Bosire Onyancha ${ }^{2}$ \\ dcrotich@hotmail.com ORCID: orcid.org/0000-0003-0974-2329 \\ onyanob@unisa.ac.za ORCID: orcid.org/0000-0002-9232-4939
}

\author{
Received: 12 January 2017 \\ Accepted: 01 February 2017
}

\begin{abstract}
Research productivity and visibility are becoming increasingly important in the individual researcher's pursuit to build his or her research reputation, be promoted to the next academic rank within an institution and gain national and international recognition among peers. This paper analyses the research trends and patterns of the academic staff of the College of Health Sciences (CHS) at Moi University in Kenya between 2002 and 2014 to gauge their research productivity and visibility. The names of the academic staff of the CHS who were in employment at the end of 2012 were listed and subjected to a visibility search on the Publish or Perish software that uses Google Scholar as its data source. The findings on output reveal the following: the trend of publication has shown an upward growth since 2007 and is projected to continue to grow as it approaches linearity, until 2025; the School of Medicine was the most prolific and visible; approximately one third of the publications in the CHS originated in the departments of epidemiology and medicine; full professors' performance exceeded that of the other ranks; researchers at the CHS rely heavily on a locally-published journal (East African Medical Journal) to publish their research; slightly over two thirds of the publications were singly authored; international collaborations were prominently visible; and most medical and health research conducted at the CHS focused on western Kenya, where Moi University is located. For higher productivity and wider visibility of CHS research, the researchers recommend additional funding; publication of the research through a variety of avenues, including open access journals, and the dissemination of the publications through social media platforms; and strengthening of the international collaboration networks, among others. For purposes of further research, the authors propose a study that will investigate the medical and health research visibility and impact across several institutions in Kenya.
\end{abstract}

Keywords: Research, medical and health research, research collaboration, Moi University, Kenya

\section{Conceptual setting}

Research productivity and visibility is increasingly becoming important in the researcher's pursuit to build his or her research reputation, be promoted to the next academic rank within an institution, and gain recognition among peers nationally and internationally (Ocholla, Mostert and Rotich, 2016, Thomson Reuters 2008). Thomson Reuters (2008) notes that universities conduct an evaluation of their research performance in order to decide what research should be supported and what should not, or which research projects and researchers should receive more support than others, especially in areas where research funding is limited. Garfield (1996) has stressed the need for the assessment of researchers' productivity and impact amid dwindling research funds by stating that "in several countries where research funding is often highly political, many of the most deserving researchers receive a small fraction of research funds in contrast to parasites who hadn't published a paper for a decade or more". When measuring productivity and visibility, the global rankings count papers published in journals that are indexed in the main global indices - such as the Science Citation Index, Web of Science or Scopus, or their equivalents for other disciplines. Thomson Reuters (2008) states that the evaluation of research performance may help university leaders "understand the institution's position relative to global and domestic standards of research production: how much research is conducted? What is its impact? How many of the faculty members' articles are published in first-class journals? Is that number of publications increasing or decreasing?" Several authors (for example, Lancaster 1991, Jacobs 2002) have observed that evaluating individual or institutional research productivity and visibility involves the analysis of the number of publications produced, assessing the extent of collaboration, and determining the quality of research being conducted.

Research productivity in academia has therefore generally been regarded in terms of the number of publications produced and published in peer-refereed journals per researcher. Publication in high-status, refereed journals, for the most part published in English, has become an important route to academic success in the competitive environment of global higher education (Altbach 2014). Nicholas and Ritchie (1978) and Hertzel (1987) refer to the studies that assess the productivity of researchers as descriptive bibliometrics (sometimes called productivity count studies), where a description

1. Daniel C Rotich is Professor in the Department of Publishing and Media Studies, Moi University, as well as a Research Fellow in the Department of Information Science, University of South Africa

2. Omwoyo Bosire Onyancha is Professor in the Department of Information Science, University of South Africa 
of the characteristics or features of a literature is the main focus (Nicholas and Ritchie 1978:10). Productivity count or descriptive bibliometrics can be used to study the number of publications in a given field, or productivity of literature in the field for the purpose of comparing the amount of research in different countries, the amount produced during different periods, or the amount produced in different subdivisions of the field by individual researchers (Stevens, as cited in Hertzel 1987:156). Hertzel (1987) observes that the method relies on the count of papers, books and other writings in the field, or often a count of those writings which have been abstracted in a specialised abstracting journal. Bibliometric and informetric studies are widely used to inform policies and decisions in political, economic, social and technological domains that affect the information flow and utilisation patterns within, between and outside institutions and countries.

Although Library and Information Science (LIS) studies of this nature may solve problems in Africa related to collection development, information retrieval, systems design, user studies, management, knowledge organisation and research evaluation (to name a few), the number of bibliometric studies are limited, and those focusing on research output in the continent are even more so. The exceptions are a few studies reported on LIS research output in Africa by West African scholars such as Aina and Mabawonku (1997), Aina and Mooko (1999), Alemna and Badu (1994), Alemna (1996, 2001), Kadiri (2001) and Mabawonku (2001). Some studies on LIS research have also emerged from Southern Africa in the last twenty-three years, creating an awareness of the overall research output from within the LIS discipline in Southern Africa and East Africa. These studies are largely based on the publication count and citation analysis of peer-refereed articles appearing in national and international LIS journals. These studies include Ocholla $(2000,2001)$, Ingwersen and Jacobs (2002), Onyancha and Ocholla (2009), Onyancha (2007), Ocholla and Ocholla (2007), Sitienei and Ocholla (2010), Lwoga and Sife (2014), and Ocholla, Ocholla and Onyancha (2013).

\section{Background to the study and problem statement}

Africa suffers from a myriad of medical and health challenges, including weak public health leadership and management; inadequate health-related legislations and their enforcements; limited community participation; extreme shortages of health workers; rampant corruption in procurement systems of medical products and technologies; a dearth of information and communication technologies; poor health financing; and lack of effective organisation and management of health services (Kirigia and Barry 2008). It is not surprising therefore to note that Africa is home to a heavy burden of both communicable and non-communicable diseases. These, and several other factors, have led to the prioritisation of research in medical and life sciences in many African countries (Narvaez-Berthelemont et al. 2002, Tijssen 2007). In their study on science in Africa, Narvaez-Berthelemont et al. (2002) observed that Africa's total contributions were mainly in the fields of clinical medicine, which accounted for $36 \%$, chemistry (14\%), and biomedical research (12\%).

In Kenya, as in many other African countries, disease was identified as one of the enemies of economic development at independence (Ndege 2005). The Republic of Kenya has taken a number of steps to deal with the challenges associated with health and medical services in the country. Addressing the public during one of the national days in Kenya, the Kenyan president said:

Fifty years ago, healthcare was inaccessible to most of our people. Health facilities were few, far between and thousands of our people died from treatable medical conditions. Today, the situation is remarkably different. Not only do we have thousands of health workers, but also services are much closer to the people as health facilities are now spread across all parts of the country. We have also achieved notable success in the areas of child and maternal health (Kenyatta, 2013).

Biomedical and health research in Kenya seems to have followed suit in terms of the volume of publications in the research field. For instance, Tijssen (2007) has observed that Kenya's research output, between 2001 and 2004, was the highest in medical and life sciences followed by natural sciences, social sciences and engineering sciences. Similarly, Narvaez-Berthelemont et al. (2002), in a study that investigated science in Africa between 1991 and 1997, observed that Kenya (among other African countries such as Nigeria) was strong in the fields of clinical medicine and biology. In a recent study that compared the productivity and visibility of researchers in Moi University and the University of Zululand, Ocholla, Mostert and Rotich (2016) discovered that Moi University's research output was concentrated in health sciences and/or medicine, with medicine topping the list of subject categories with the highest number of publications (339), accounting for $35.1 \%$ of the total number of publications published by academic staff of Moi University. The study, however, did not delve into the patterns and nature of research in Moi University's health and medical sciences research. This paper is a follow-up to Ocholla, Mostert and Rotich's paper (2016) and aims to assess the productivity and visibility of researchers in the College of Health Sciences (CHS) at Moi University. The paper seeks to:

- $\quad$ examine the trend of publication of health and medical sciences research;

- identify the most prolific authors, departments and schools within the CHS;

- determine the most commonly-used journals to disseminate the health and medical sciences research;

- examine the level of collaboration among the authors engaged in CHS's medical and health sciences research; and

- identify the most-researched topics in health and medical sciences research at the CHS.

The College of Health Sciences (CHS), formerly the Faculty of Health Sciences, was established in 1988. The CHS comprises four schools namely, the School of Medicine, School of Public Health, School of Dentistry, and the School of 
Nursing. It is worthy stating that, when the CHS was re-organised into the four schools, the majority of the existing senior academic staff were moved to the School of Medicine. The re-organisation of the CHS into schools was due to changing needs in the provision and training of healthcare professionals in Kenya and the region. The academic staff of CHS have engaged in various research projects and collaborations with local and international organisations in their endeavour to find solutions to the numerous health problems that exist not only in western Kenya but also in the entire country. The CHS at Moi University is the only medical school in western Kenya that offers broad academic programs in the areas of medicine, public health, dentistry and nursing. In addition, the Moi Teaching and Referral Hospital (MTRH), one of the two national teaching and referral hospitals in Kenya, is attached to the CHS, thereby making the College distinct, with most doctors working at the hospital also lecturing at the CHS. The meeting of academics and practitioners has led to a unique collaborative venture with the international community, with the aim of improving, not only research, but also the livelihoods of the populace in western Kenya; hence the current study to review the performance of the CHS in research.

\section{Research method and procedure}

A list of academic staff in the four schools of the CHS at Moi University was obtained from the university's Human Resources department. The schools that comprise the CHS are Dentistry, Medicine, Nursing, and Public Health. A total of 211 academic staff members were targeted for the study. At Moi University, there are seven levels of academic rank: graduate assistant or research assistant; tutorial fellow or junior research fellow; assistant lecturer; lecturer or research fellow; senior lecturer or senior research fellow; associate professor or associate research professor; and professor or research professor (Moi University 2012). The names of the academic staff were used to search for publications in Google Scholar using an advanced search strategy in the Publish or Perish (PoP) software. The PoP software program, introduced by Anne Harzing in 2006, "uses Google Scholar queries to obtain citation information, which is then analysed and converted to a number of statistics" (Harzing, 2011). The PoP software allows one to conduct searches on and analyses of author impact, journal impact and general citations of publications. The author impact platform is most suited when one is searching for publications authored by a given author while the journal impact offers the searcher an opportunity to search and analyse a particular journal. The citation analysis search platform offers several strategies with which one can conduct a search through the software program. The platform can be considered as equivalent to an advanced search tool found in many bibliographic databases. Through the citation analysis search platform, one can search Google Scholar by author name, publication, journal ISSN, words (in title or text), or year of publication. A combination of search queries can be conducted at the same time.

The researchers used the author impact search platform to conduct searches via the names of authors who are affiliated with the departments in the CHS. The searches were limited to the period between 2002 and 2014 . The approach was adopted in order to extract only those publications that could represent research output of the CHS and its affiliate departments. Different variations of the authors' names were used to extract the data, which was then saved in worksheets prepared using Microsoft Excel software. The results from the searches were subjected to further editing to remove duplications of co-authored publications and those with similar names outside medical and health sciences fields.

Data analysis took different forms, depending on the variable that was under investigation. Once the trend or pattern of the growth of publications in the CHS was determined, the researchers sought to forecast the growth of the publications beyond the period under study in this paper, by subjecting the data to time series analysis using the ARIMA model. The SPSS package was used to access the ARIMA model to forecast future trends in publications growth.

VosViewer software was used to map research collaboration. The text file that contained the names of the authors was subjected to analysis using VosViewer by setting the number of publications threshold per author at two papers. A total of 454 authors met the threshold. The analysis yielded a total of ninety clusters of two or more authors each, 3,507 links and total link strength value of 7,644. The software was also used to analyse the publication titles in order to determine the most-researched topics in medical and health sciences at the CHS. Again, the word occurrence threshold was set to at least two words. A total of 1,568 terms met the threshold. Upon the removal of terms that were considered 'noise' (for example, stop words), a total of 313 terms were obtained for mapping. Figure 5 provides the network map of the 313 terms which were the most common in the titles of outputs published by CHS authors at Moi University.

\section{Results}

This section presents findings under the following sub-headings:

- $\quad$ Trend of medical and health research at the CHS

- Contribution of CHS's schools and departments to medical and health research

- $\quad$ Authors contributing to medical and health research at the CHS

- Journals publishing CHS's medical and health research

- Mapping research collaboration in the CHS

- Most commonly-researched topics in medical and health research at the $\mathrm{CHS}$

\subsection{Trend of medical and health research at the CHS}

Figure 1 shows that the CHS at Moi University has experienced a steady growth in the number of publications. There was, however, a turbulent period between 2004 and 2007, after which the upward movement has continued to manifest itself. From only three $(0.59 \%)$ papers in 2002, the number of papers grew to reach $107(20.89 \%)$ in 2014. The upward trend of 
growth exhibited in Figure 1 can be attributed to a number of factors including an increase in the number of researchers in the CHS and the availability of research funds, among other factors. From the graph in Figure 1, the rate of linear growth is $80 \%\left(R^{2}=0.8009\right)$, which implies that the growth of publications is approaching linearity. This trend of publication is likely to continue, as shown in Table 1 and Figure 2. As mentioned in the methodology section, an ARIMA model analysis was conducted to forecast the trend of growth of the publications for the next eleven years, 2015 to 2025 . Table 1 and Figure 2 reveal that the number of papers will grow at a lineal rate from about 126 in 2015 to approximately 354 papers in 2025. Table 1 provides two other scenarios of growth, namely the upper control limit (UCL) and lower control limit (LCL).

Figure 1 Trend of papers of medical and health research publications at Moi University

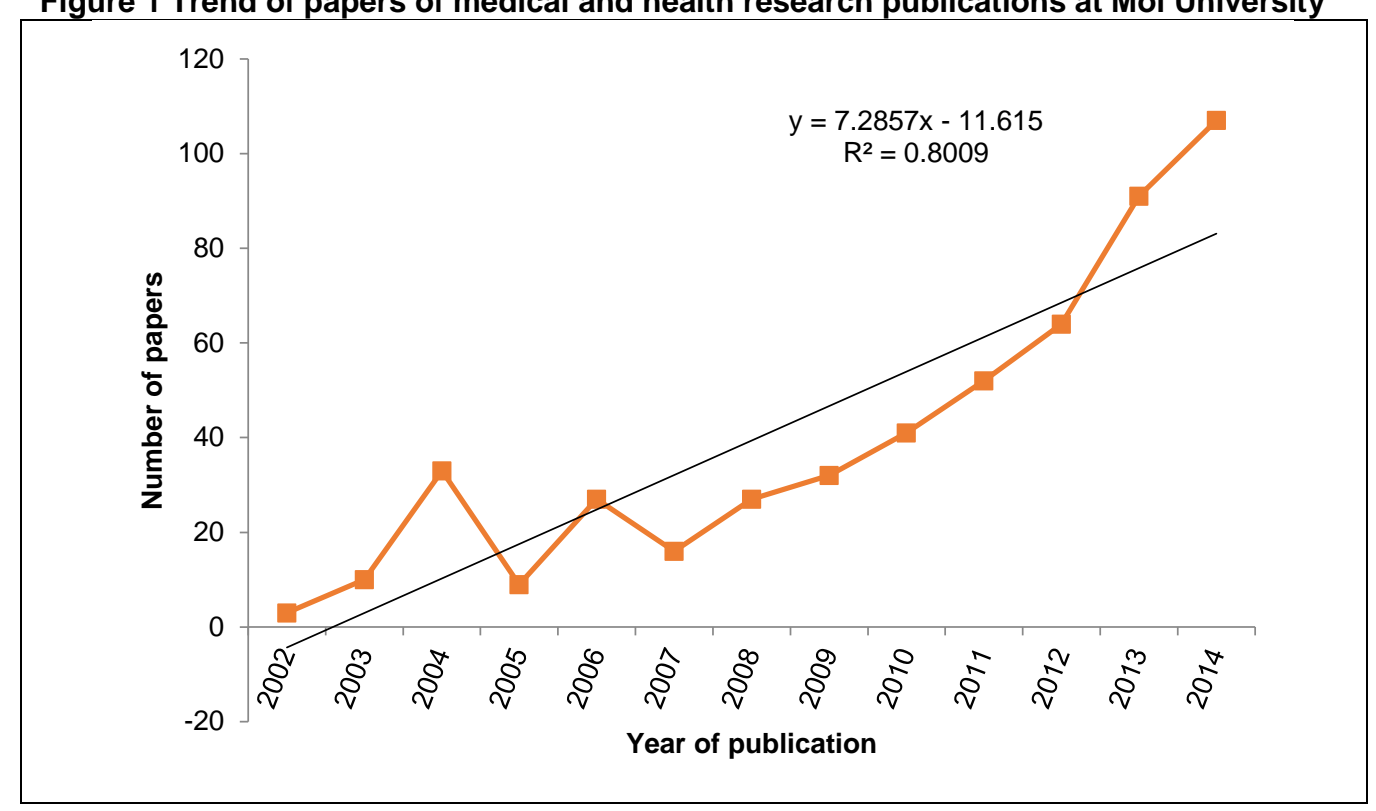

Table 1 Forecasting the growth of papers at the CHS, Moi University

\begin{tabular}{|c|c|c|c|c|c|c|c|c|c|c|c|}
\hline & 2015 & 2016 & 2017 & 2018 & 2019 & 2020 & 2021 & 2022 & 2023 & 2024 & 2025 \\
\hline Forecast & 126.54 & 149.30 & 172.05 & 194.80 & 217.56 & 240.31 & 263.06 & 285.82 & 308.57 & 331.32 & 354.08 \\
\hline UCL & 154.45 & 185.04 & 221.04 & 261.09 & 304.23 & 349.85 & 397.63 & 447.34 & 498.80 & 551.90 & 606.55 \\
\hline LCL & 98.64 & 113.56 & 123.06 & 128.51 & 130.89 & 130.77 & 128.49 & 124.30 & 118.34 & 110.74 & 101.60 \\
\hline
\end{tabular}

Figure 2 Forecasting the growth of papers at the CHS, Moi University

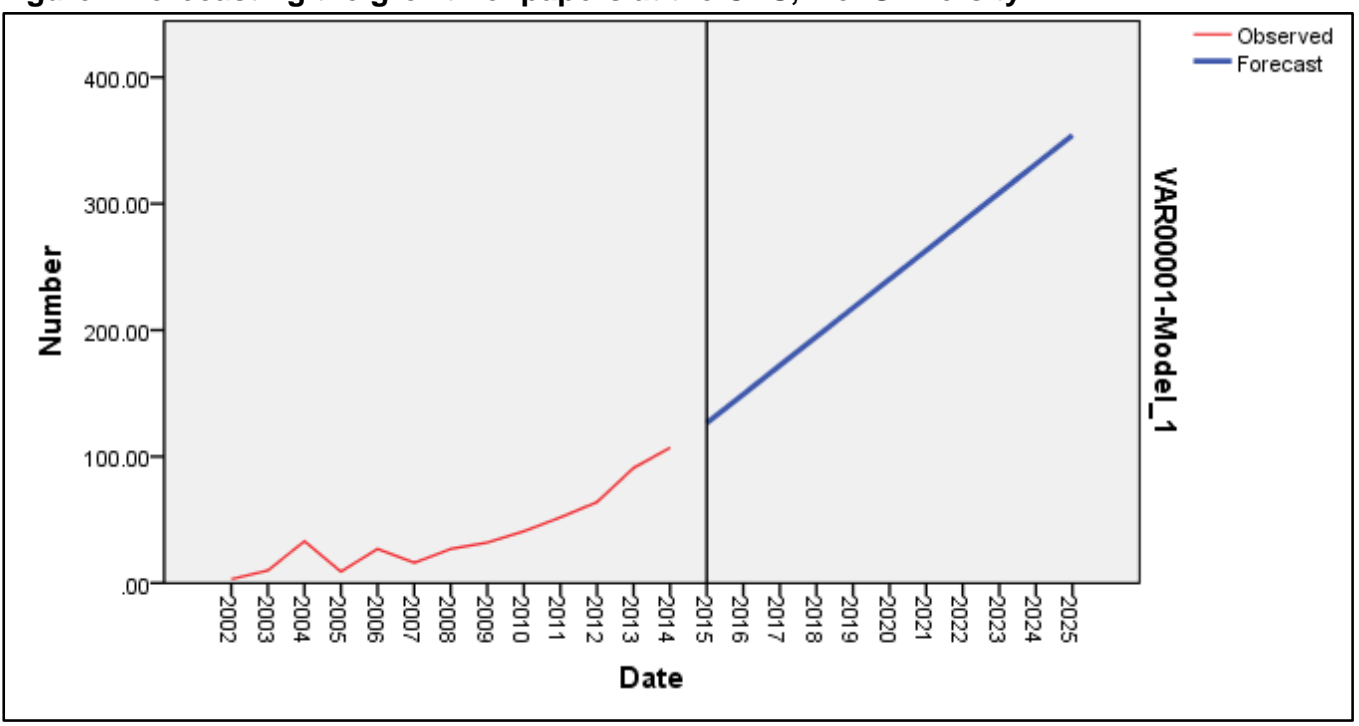

\subsection{Contribution of CHS's schools and departments to medical and health research}

In terms of the distribution of the papers according to the schools in the CHS, the School of Medicine produced the largest number of papers (390), accounting for $76 \%$ of the total number of papers produced in the College. The School of Public Health produced less than half the number of papers produced by the School of Medicine (104 or 20\%) while the School of Nursing and the School of Dentistry published sixteen (3\%) and two (1\%) papers respectively. This pattern of publication may be attributed to several factors, among them the number of researchers in each school, research area/s focused on 
most in the CHS, research funding and international collaborations, and the national preferences as far as research in medicine and health is concerned.

Figure 3 Schools' contribution to health research in Moi University ( $N=512)$

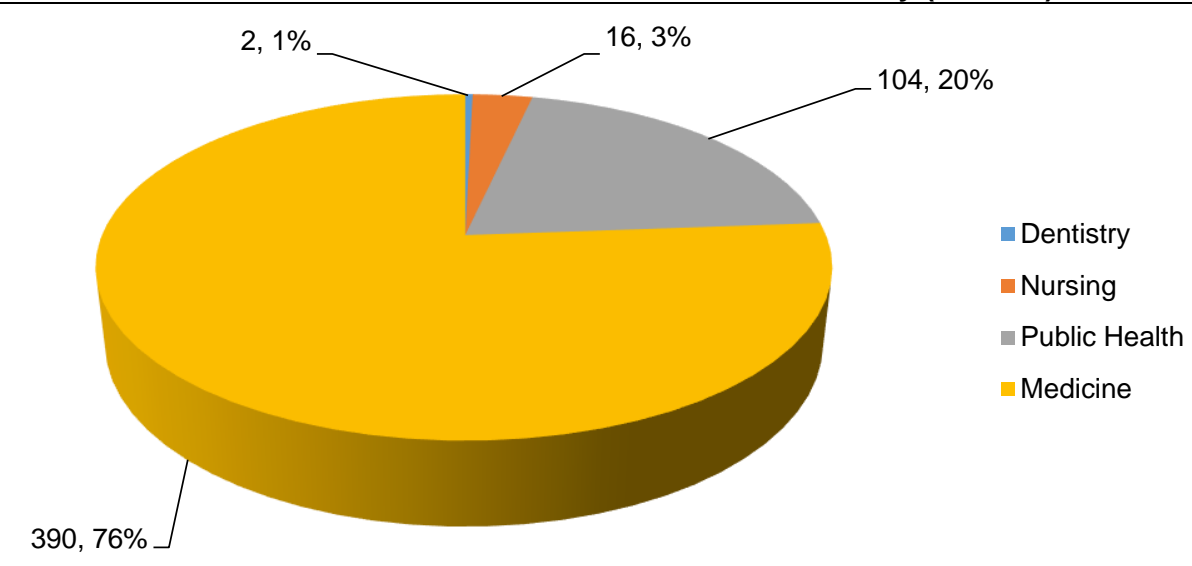

Table 2 Research output of the CHS by department ( $\mathrm{N}=512)$

\begin{tabular}{|c|c|c|c|c|}
\hline Number & Rank & Department & No. of papers & Percentage \\
\hline 1 & 1 & Epidemiology and Nutrition & 88 & 17.19 \\
\hline 2 & 2 & Medicine & 80 & 15.63 \\
\hline 3 & 3 & Child Health and Paediatrics & 55 & 10.74 \\
\hline 4 & 4 & Surgery and Anaesthesiology & 44 & 8.59 \\
\hline 5 & 5 & Reproductive Health & 29 & 5.66 \\
\hline 6 & 6 & Behavioural Sciences & 28 & 5.47 \\
\hline 7 & 7 & Pharmacology and Toxicology & 24 & 4.69 \\
\hline 8 & 8 & Medical Education & 23 & 4.49 \\
\hline 9 & 9 & Family Medicine & 22 & 4.30 \\
\hline 10 & 10 & Mental Health & 21 & 4.10 \\
\hline 11 & 11 & Medical Biochemistry & 15 & 2.93 \\
\hline 12 & 12 & Medical Microbiology and Parasitology & 14 & 2.73 \\
\hline 13 & 13 & Immunology & 10 & 1.95 \\
\hline 14 & 14 & Environmental Health & 9 & 1.76 \\
\hline 15 & 15 & Haematology and Blood Transfusion & 8 & 1.56 \\
\hline 16 & 15 & Orthopaedics and Rehabilitation & 8 & 1.56 \\
\hline 17 & 16 & Health Policy and Management & 7 & 1.37 \\
\hline 18 & 17 & Medical Physiology & 6 & 1.17 \\
\hline 19 & 17 & Midwifery and Gender & 6 & 1.17 \\
\hline 20 & 18 & Child, Adult and Mental Health & 5 & 0.98 \\
\hline 21 & 19 & Community Health, Nursing Administration and Education & 5 & 0.98 \\
\hline 22 & 20 & Radiology and Imaging & 2 & 0.39 \\
\hline 23 & 21 & Conservative Dentistry and Prosthetics & 1 & 0.20 \\
\hline 24 & 21 & Human Pathology and Forensic Medicine & 1 & 0.20 \\
\hline \multirow[t]{2}{*}{25} & 21 & Maxillofacial Surgery, Oral Medicine/Pathology and Radiology & 1 & 0.20 \\
\hline & & TOTAL & 512 & 100.00 \\
\hline
\end{tabular}

There are twenty-five departments that comprise the CHS. The most prolific department by publication count was Epidemiology and Nutrition, which yielded a total of eighty-eight (17.19\%) papers followed by Medicine (eighty, 15.63\%), Child Health and Paediatrics (fifty-five, 10.74\%), and Surgery and Anaesthesiology (forty-four, 8.59\%). The remaining departments produced fewer than twenty-five papers each, with three of them (Conservative Dentistry and Prosthetics, Human Pathology and Forensic Medicine, and Maxillofacial Surgery, Oral Medicine/Pathology and Radiology) publishing 
only one article each between 2002 and 2014. It is noteworthy that the research areas that are focused on by most researchers seem to become clearer as one moves from the analysis of the publications according to schools to departments. If the names of the schools reflect the sub-disciplines or fields of study and research, then it is safe to say that issues around epidemiology and nutrition, child health and paediatrics, surgery, and reproductive health have taken centre stage in the research conducted at the CHS, Moi University. The strong performance of some of the departments (those with the highest number of publications within $\mathrm{CHS}$ ) can be attributed to a number of factors; firstly, the number and rank of academic staff in the departments (the majority of staff in the top five departments are well established and at the grades of senior lecturer and above); secondly, collaborations with international organisations which fund research projects in the research areas specific to said departments; and thirdly, the formation of a number of research groups within the concerned departments, based on common areas of research. The commonality is evident in areas of nutrition, child health, paediatrics and reproductive health. An analysis of the topics of research as reflected in the titles of the papers is provided in Figure 5.

\subsection{Authors contributing to medical and health research at the CHS}

The most prolific authors are listed in Table 3 . There were a total of 1,427 authors who contributed to health and medical sciences research at Moi University. The CHS at Moi University consists of a total of eighty-nine academic staff members who rank from graduate assistant to full professor. Of these, S. Kimaiyo authored the most papers (fifty-three), accounting for $10.35 \%$ of the total number of papers (512) published by the CHS between 2002 and 2014. F. Esamai was placed in the second position with forty-eight $(9.38 \%)$ papers while S. Ayaya authored forty-five $(8.79 \%)$ to end the list of CHS staff members who produced at least forty papers in the period under investigation.

Table 3 Twenty-five most productive authors $(N=512)$

\begin{tabular}{|c|c|c|c|c|}
\hline Number & Rank & Author & No. of papers & Percentage \\
\hline 1 & 1 & Kimaiyo, S. & 53 & 10.35 \\
\hline 2 & 2 & Esamai, F. & 48 & 9.38 \\
\hline 3 & 3 & Ayaya, S. & 45 & 8.79 \\
\hline 4 & 4 & Vreeman, R. & 41 & 8.01 \\
\hline 5 & 5 & Wools-Kaloustian, K. & 40 & 7.81 \\
\hline 6 & 6 & Braitstein, $\mathrm{P}$. & 38 & 7.42 \\
\hline 7 & 7 & Siika, A. & 33 & 6.45 \\
\hline 8 & 7 & Ayuku, D. & 32 & 6.25 \\
\hline 9 & 9 & Nyandiko, W.M. & 30 & 5.86 \\
\hline 10 & 9 & Mwangi, A. & 25 & 4.88 \\
\hline 11 & 11 & Atwoli, L. & 24 & 4.69 \\
\hline 12 & 12 & Rotich, J. & 22 & 4.30 \\
\hline 13 & 12 & Kuremu, R. & 20 & 3.91 \\
\hline 14 & 14 & Sidle, J.E. & 19 & 3.71 \\
\hline 15 & 15 & Musick, B. & 19 & 3.71 \\
\hline 16 & 15 & Ayuo, P. & 18 & 3.52 \\
\hline 17 & 17 & Menya, D. & 18 & 3.52 \\
\hline 18 & 17 & Carter, J. & 18 & 3.52 \\
\hline 19 & 17 & Diero, L. & 18 & 3.52 \\
\hline 20 & 17 & Yiannoutsos, C. & 17 & 3.32 \\
\hline 21 & 21 & Buziba, N. & 16 & 3.13 \\
\hline 22 & 21 & Liechty, E. & 16 & 3.13 \\
\hline 23 & 23 & Gisore, $\mathrm{P}$. & 16 & 3.13 \\
\hline 24 & 23 & Ettyang, G. & 16 & 3.13 \\
\hline 25 & 23 & Ndege, S. & 15 & 2.93 \\
\hline
\end{tabular}

The three most prolific authors in the CHS belong to the Departments of Medicine (two) and Child Health and Paediatrics (one). The productivity of these authors is based mostly on their collaborations with other authors - both local and international - as well as their attraction of research funds. The three authors are also professors in their respective departments, hence they have progressed in academic rank and accumulated more research publications over time. There were a number of authors from outside Moi University who had collaborated with CHS scholars. The most prolific among 
these were R. Vreeman, K. Wools-Kaloustian and P. Braitstein who published forty-one (8.01), forty (7.81\%) and thirtyeight $(7.42 \%)$ papers respectively.

When the papers were distributed according to the position or rank of individual authors, it was observed that the seven full professors (simply hereinafter referred to as professors or P) working in the CHS collectively produced 139 papers, averaging 19.86 papers per head. Associate professors (AP), who numbered eleven, published a total of 186 papers, thereby accounting for an average of 16.91 papers per person. Senior lecturers (SL) (19) produced an average of 11.11 papers per head based on their total research output of 211, while the average number of publications per person in the category of lecturers (L), who were the largest in number (forty-four), was 5.64 based on their collective total research output of 248 papers. The four assistant lecturers (AL) produced a total of 18 papers, thereby averaging 4.50 papers per person. In the final category of staff member, the three tutorial fellows (TF) published eight papers, thereby yielding an average score of 2.67 papers per person. It therefore follows that, on average, the category of professor was the most prolific followed by associate professors, senior lecturers, lecturers, assistant lecturers and tutorial fellows. This pattern is in line with the ranking order of positions at the university. The lowest academic rank at Moi University is that of graduate assistant (GA), a holder of a bachelor's degree with at least an upper second-class pass from a recognised university, however no research output from this rank was visible in this study. For one to be appointed to the position of TF, he/she must have a bachelor's degree and a master's degree from a recognised/accredited university and must demonstrate potential for teaching or research during the appointment interview. This position is on contract, renewable annually based on the holder registering for a doctoral degree and on research output during the contract period. The holder of an AL position must have the same qualification as a TF, however, this position is on permanent (tenure) terms (since 2015, this position no longer exists). Appointment to the position of lecturer is based on the number of publications in addition to the holder having obtained a doctorate degree or its equivalent from a recognised/accredited university. In the $\mathrm{CHS}$, in the Schools of Dentistry or Medicine, holders of a master's degree (M.Med/MDS) with three years' teaching experience and the required number of publications are appointed to lecturer position. Promotion from the position of senior lecturer to professor is based on research output, teaching experience, supervision of postgraduate students and attraction of research funds (Moi University 2015). Table 3 (above), which presents the top twenty-five authors, contains names of authors occupying the higher ranks on the academic ladder. These include S. Kimaiyo (AP), F. Esamai (P), S. Ayaya (P), A. Siika (SL), D. Ayuku (AP), W.M. Nyandiko (AP) and A. Mwangi (SL).

Table 4 Author productivity index in health sciences research $(N=1,427)$

\begin{tabular}{cccccc}
\hline No. of papers & Number of authors & Percentage & No. of papers & Number of authors & Percentage \\
\hline 1 & 973 & 68.19 & 16 & 3 & 0.21 \\
2 & 206 & 14.44 & 17 & 3 & 0.21 \\
3 & 73 & 5.12 & 18 & 2 & 0.14 \\
4 & 45 & 3.15 & 19 & 1 & 0.07 \\
5 & 26 & 1.82 & 20 & 2 & 0.14 \\
6 & 20 & 1.40 & 22 & 1 & 0.07 \\
7 & 11 & 0.77 & 24 & 1 & 0.07 \\
8 & 17 & 1.19 & 26 & 1 & 0.07 \\
9 & 13 & 0.91 & 30 & 2 & 0.14 \\
10 & 8 & 0.56 & 39 & 1 & 0.07 \\
11 & 2 & 0.14 & 40 & 1 & 0.07 \\
12 & 1 & 0.07 & 41 & 1 & 0.07 \\
13 & 4 & 0.28 & 44 & 1 & 0.07 \\
14 & 4 & 0.28 & 48 & 1 & 0.07 \\
15 & 2 & 0.14 & 53 & 1 & 0.07 \\
\hline
\end{tabular}

In terms of the number of $n^{a}$ authors who have published $n^{p}$ number of papers each, Table 4 illustrates that the majority of authors (973; 68.19\%) published one article each between 2002 and 2014. Those authors who published two papers each were 206 (14.44\%); three papers each were seventy-three $(5.12 \%)$; four papers each were forty-five $(3.15 \%)$; five papers each were twenty-six $(1.82 \%)$; and six papers each totalled twenty $(1.40 \%)$. This pattern seems to follow the theoretical basis for Lotka's law of author productivity which states that "for any body of literature, there will be a substantial number of authors who have each contributed only one publication, a small number of authors who have each contributed a small number of publications, and a very small group of authors who have each contributed a substantial number of publications" (Wallace 1989: 10). Although this law seems to apply to authorship patterns depicted in Table 4, which shows all authors who contributed to health and medical sciences research with at least one person affiliated with the CHS at Moi University, the law may also apply to the author productivity when assessed by their academic ranks. A very small number of authors in the categories of AP and P published a substantive number of publications each, while a large number of authors in the lower categories produced a smaller number of papers each. 


\subsection{Journals publishing CHS's medical and health research}

An analysis of the journals through which the authors disseminate health and medical sciences research conducted at the $\mathrm{CHS}$ at Moi University reveals that a high number of papers appear in journals that are either published in Africa or simply bear the name of the continent. At the top of the list of journals, with the largest number of papers, was the East African Medical Journal which published a total of ninety-one (17.77\%) papers. This is a local journal (published in Kenya) and sponsored by the Kenya Medical Association. The journal is archived in African Journals Online (AJOL), a non-profit organisation dedicated to improving online visibility and access to the published scholarly research of African-based academics. Other journals among the top fifteen in which authors based in the CHS publish include PLOS ONE, which yielded nineteen (3.71\%) papers. PLOS ONE is a multidisciplinary, peer-reviewed open-access (OA) journal and therefore not necessarily dedicated to the field of health and medical sciences. Its preference by staff members in the CHS is perhaps testimony to the acceptance of OA scholarly publishing among some researchers in the College. In the third position is the East African Journal of Public Health, which publishes primary research on a range of topics including community medicine, epidemiology, nutrition, behavioural sciences, health promotion, health education, and communicable and noncommunicable disease. The journal published sixteen (3.13\%) papers emanating from the CHS. The next three journals listed in Table 5 publish research on the broad area of HIV/AIDS. Collectively, these three journals published a total of thirtytwo papers, accounting for $6.25 \%$ of the total number of papers published by the CHS between 2002 and 2014. All in all, $\mathrm{CHS}$ research was published in 225 sources, covering various diverse topics in health and medical sciences.

Table 5 Sources publishing health sciences research $(N=512)$

\begin{tabular}{ccccc}
\hline Number & Rank & Journal/source name & No. of papers & Percentage \\
\hline 1 & 1 & East African Medical Journal & 91 & 17.77 \\
2 & 2 & PLOS ONE & 19 & 3.71 \\
3 & 3 & East African Journal of Public Health & 16 & 3.13 \\
4 & 4 & Journal Of Acquired Immune Deficiency Syndromes (JAIDS) & 14 & 2.73 \\
5 & 5 & Journal of the International Aids Society & 11 & 2.15 \\
6 & 6 & Aids & 7 & 1.37 \\
7 & 6 & African Health Sciences & 7 & 1.37 \\
8 & 6 & Food \& Nutrition Bulletin & 7 & 1.37 \\
9 & 6 & Public Health Action & 7 & 1.37 \\
10 & 7 & East and Central African Journal of Surgery & 6 & 1.17 \\
11 & 7 & The Pediatric Infectious Disease Journal & 6 & 1.17 \\
12 & 7 & Indian Journal of Palliative Care & 6 & 1.17 \\
13 & 7 & Annals of African Surgery & 6 & 1.17 \\
14 & 8 & Journal of Biochemical and Molecular Toxicology & 5 & 0.98 \\
15 & 8 & Journal of Biology, Agriculture and Health Care & 5 & 0.98 \\
\hline
\end{tabular}

\subsection{Mapping research collaboration in the CHS}

Figure 4 and Tables 6 and 7 present the findings on author collaboration, often considered in bibliometrics circles as the proxy to measure research collaboration among researchers (see Diodato 1994: 4, Laudel 2001: 369, Glazel 2002, Gauthier 1998). The colours of the nodes in the figures depict the authors who belong to the same cluster. The larger the author's label or name and node in Figure 4, the higher the weight of his/her research collaboration. The weight of collaboration is clearly shown in Table 7 . Figure 4 consists of a total of 454 authors who contributed at least two papers each, while Table 7 provides a glimpse of the extent or weight of research collaboration of the authors who collaborated with at least forty authors. It was found that S. Kimaiyo collaborated the most, registering a weight link score of 108 , implying that he collaborated with 108 authors, followed by K. Wools-Kaloustian (103), and F. Esamai (100). An interesting finding in the assessment of the top research collaborators is the presence of authors who are not employees of the CHS at Moi University, a situation that implies external research collaboration or, at best, international collaboration. The cluster analysis reveals that there were 87 clusters of at least two authors each. The distribution of names according to the clusters that contained ten or more names of authors is presented in Table 6.

It was observed that all the clusters above have international representation, implying that most research in medical and health sciences at Moi University is conducted through international collaboration. The clusters are based on the research themes within the CHS and Academic Model Providing Access to Healthcare (AMPATH) areas of research interest that may be dictated by the funders. The researchers have grouped themselves according to areas in which they will carry out research; the groups are composed of researchers of diverse specialisations. 
Table 6 Clusters with at least ten or more names of participating authors

\begin{tabular}{|c|c|c|}
\hline Cluster & No. authors & Names of participating authors \\
\hline One & 31 & $\begin{array}{l}\text { S. Esamai, C. Tenge, H. Mabeya, E. Liechty, I. Marete, D. Hibberd, J. Moore, K. Hambidge, R. } \\
\text { Goldenberg, S. Goudar, E. McClure, A. Patel, L. Wright, N. Krebs, O. Pasha, W. Carlo, R. Derman, B. } \\
\text { Kodkany, E. Chomba, A. Garces, M. Koso-Thomas, F. Althabe, S. Saleem, J. Belizan, D. Wallace, P. } \\
\text { Buekens, A. Jobe, C. Bose, A. Manasyan, S. Stalls and J. Simba. }\end{array}$ \\
\hline Two & 15 & $\begin{array}{l}\text { R. Vreeman, P. Braitstein, S. Ayaya, P. Gisore, W. Nyandiko, D. Ayuku, L. Atwoli, A. Kamanda, J. Koech, } \\
\text { L. Embleton, S. Wish, E. Kamaara, M. Turissini, R. Kengthe and C. Otieno. }\end{array}$ \\
\hline Three & 17 & $\begin{array}{l}\text { J. Carter, N. Busakhala, R. Strother, F. Njuguna, P. Loehrer, A.M. Kryzanowsk, J. Skiles, G. Kasper, S. } \\
\text { Mostert, B. Rosen, F. Asirwa A. Griest, A. Mega, E. Njiru, E. Orango, and S. Washington. }\end{array}$ \\
\hline Four & 14 & $\begin{array}{l}\text { S. Kimaiyo, K. Wools-Kaloustian, A. Siika, A. Mwangi, J.E. Sidle, L. Diero, B. Musick, J. Rotich, C. } \\
\text { Yiannoutsos, E. Sang, R. Einterz, J. Mamlin, C. Shen, and W.M. Tierney. }\end{array}$ \\
\hline Five & 15 & $\begin{array}{l}\text { A. Tshefu, G. Darmstadt, E. Adejuyigbe, A. Ayede, A. Baqui, S. Wall, R. Wammanda, A. Zaidi, R. Bahl, } \\
\text { C. Engmann, E. Longombe, S. Qazi, S. Saha and N. Rollins. }\end{array}$ \\
\hline Six & 15 & $\begin{array}{l}\text { D. Shaffer, E. Hogg, F. Sawe, A. Asmelash, L. Mohapi, R.M. Hosseinipour, J. Hakim, S. Lockman, T. } \\
\text { Chipato, Y. Zheng, J. Mclntyre, J. Rooney, E. Stringer, J. Currier, and M. Highes. }\end{array}$ \\
\hline Seven & 15 & $\begin{array}{l}\text { D. Menya, P. Ayuo, C. Simiyu, A. Obala, B. Khwa-Otsyula, D. Odhiambo, W. Omeara, R. Downing, D. } \\
\text { Chelagat, P. Chege, J. Demaeseneer, E. Mwaliko, J. Armstrong, P. Masibo and A. Githeko. }\end{array}$ \\
\hline Eight & 12 & $\begin{array}{l}\text { W. Owino-Ongor, J.B. Baliddawa, C. Justice, K. Bryant, S. Martino, R. Papas, K. Carroll, S. Maisto, M. } \\
\text { Mwaniki, O. Omolo, R. Songole, and B.N. Gakinya. }\end{array}$ \\
\hline
\end{tabular}

Figure 4 Author collaboration in health and medical sciences research at the CHS

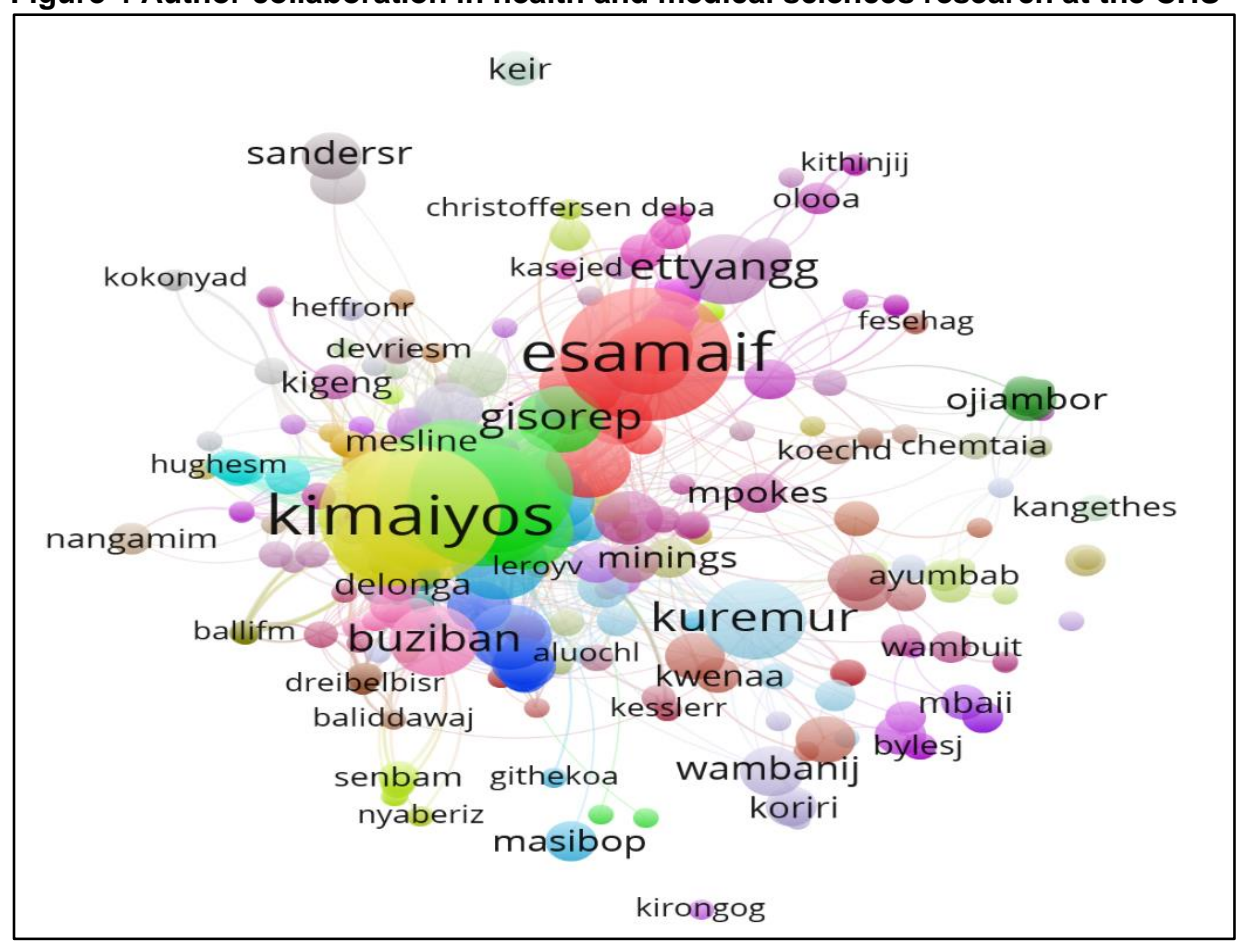

\subsection{Most commonly-researched topics in medical and health research at the CHS}

The topics of the research focus, drawn from the titles of papers published by authors in the CHS, are provided in Figure 5 . There were 313 terms (and phrases) that met the frequency of occurrence threshold and which were considered to be reflective of the research topics. Of these research topics (terms in titles), 'Kenya' was the most common with an occurrence frequency of 128, followed by 'western Kenya' (120), 'child' (fifty), 'HIV' (forty-eight), 'Eldoret' (thirty-seven), 'Patient' (thirtyseven), 'referral hospital' (thirty-one), 'Moi teaching' (twenty-five), 'community' (twenty-one), 'prevalence' (nineteen), 'treatment' (nineteen), and 'infection' (eighteen).

The same terms had the most number of links, in descending order, as follows: 'Kenya' (117), 'western Kenya' (114), 'HIV' (sixty-five), 'child' (sixty-seven), 'Eldoret' (forty-eight), 'patient' (forty-eight), 'prevalence' (forty-seven), 'referral hospital' (forty), 'community' (forty), and 'infection' (thirty-nine). The two analyses of the most common terms in the titles (frequency of occurrence and weight of links) reveal that staff members at the CHS largely conduct research on a variety of topics but more specifically on child health care and HIV/AIDS in western Kenya or Kenya at large. The other contextual setting relates to the institutional context of research, namely the Moi University Referral Hospital in Eldoret. 
Table 7 Strength of collaboration among top health and medical science researchers at the CHS

\begin{tabular}{|c|c|c|c|}
\hline Label & Cluster & Weight<Links> & Weight $<$ Total link strength $>$ \\
\hline Kimaiyo, S. & 4 & 108 & 307 \\
\hline Wools-Kaloustian, K. & 4 & 103 & 267 \\
\hline Esamai, F. & 1 & 100 & 339 \\
\hline Siika, A. & 4 & 73 & 177 \\
\hline Mwangi, A. & 4 & 69 & 143 \\
\hline Sidle, J. & 4 & 67 & 134 \\
\hline Vreeman, R. & 2 & 66 & 220 \\
\hline Tenge, $\mathrm{C}$. & 1 & 62 & 100 \\
\hline Braitstein, $P$. & 2 & 61 & 233 \\
\hline Ayaya, S. & 2 & 59 & 214 \\
\hline Hogan, J. & 35 & 59 & 99 \\
\hline Diero, L. & 4 & 57 & 111 \\
\hline Mabeya, $\mathrm{H}$. & 1 & 57 & 102 \\
\hline Menya, D. & 7 & 56 & 97 \\
\hline Gisore, $\mathrm{P}$. & 2 & 54 & 105 \\
\hline Musick, B. & 4 & 52 & 125 \\
\hline Sidlej, E. & 4 & 52 & 88 \\
\hline Ayuo, P. & 7 & 51 & 92 \\
\hline Buziba, N. & 10 & 50 & 86 \\
\hline Liechty, E. & 1 & 50 & 210 \\
\hline Carter, J. & 3 & 49 & 90 \\
\hline Nyandiko, W. & 2 & 48 & 156 \\
\hline Rotich, J. & 4 & 48 & 82 \\
\hline Yiannoutso, S.C. & 4 & 48 & 115 \\
\hline Naanyu, V. & 33 & 48 & 70 \\
\hline Ayuku, D. & 2 & 47 & 142 \\
\hline Marete, I. & 1 & 47 & 73 \\
\hline Busakhala, N. & 3 & 44 & 92 \\
\hline Sang, E. & 4 & 43 & 88 \\
\hline Tshefu, A. & 5 & 42 & 86 \\
\hline Hibberd, P. & 1 & 41 & 149 \\
\hline
\end{tabular}

\section{Discussion, conclusions and recommendations}

The study sought to investigate the productivity and visibility of $\mathrm{CHS}$ academics or researchers at Moi University, Kenya. The findings have revealed that research at the CHS has witnessed an upward trend in the number of publications, as shown in Figure 1. The number of publications visible in 2002 was three, rising to thirty-three in 2004, but falling to sixteen in 2007, followed by a steady rise to 107 in 2014. Poreau (2015) has reported similar studies in public health research in South Africa where the number of publications reached a high level after the apartheid regime. In India, public health research output witnessed an annual increase of $42 \%$ between 2000 and 2010 . The steady rise of output at CHS could have been because of a number of factors, including more research being done at the College, an increase in the number of researchers, publishing research output in visible and refutable journals, and availability of research funds, among other factors. The projections after the year 2014 reveal that the trend is likely to continue in a linear pattern until 2025, particularly if the same conditions persist. It has been further noted that academic staff members at CHS demonstrate higher productivity as they climb the academic ladder. This finding is consisted with the findings of Pagel and Hudetz (2011) who observed that scholarly productivity is related to faculty rank among academic neurosurgeons in selected accredited university departments in the United States of America (USA). The authors' findings further found a correlation between higher productivity and access to research funds: those who have access to research funds are more productive than those who have no access or little research funding and therefore, based on their high research productivity, more likely to be promoted to higher academic ranks, thereby giving the Matthew Effect credence in academia (Diodato 1994, Lariviere and Gingras 2010). Diodato (1994) explains the Matthew Effect thus: 
The success-breeds-success or rich-gets-richer phenomenon. In scholarship this occurs when already well-known individuals receive disproportionately high recognition for their work compared to the relatively low recognition received by lesser known colleagues who do comparable work. The rewards may be grant money, prizes, honors, or citations.

This phenomenon may explain why those occupying higher ranks of senior lecturer to professor had a higher number of publications and were more visible than junior colleagues in the CHS. The pattern further follows the requirements set out in the appointment and promotion guidelines of Moi University whereby, for one to be promoted to the next level, he/she must have published a certain number of journal articles. Promotion and appointment in Moi University to any academic rank above lecturer position require that one must have published at least five journal articles apart from meeting other requirements that include teaching experience, community engagement and conference attendance (Moi University 2012).

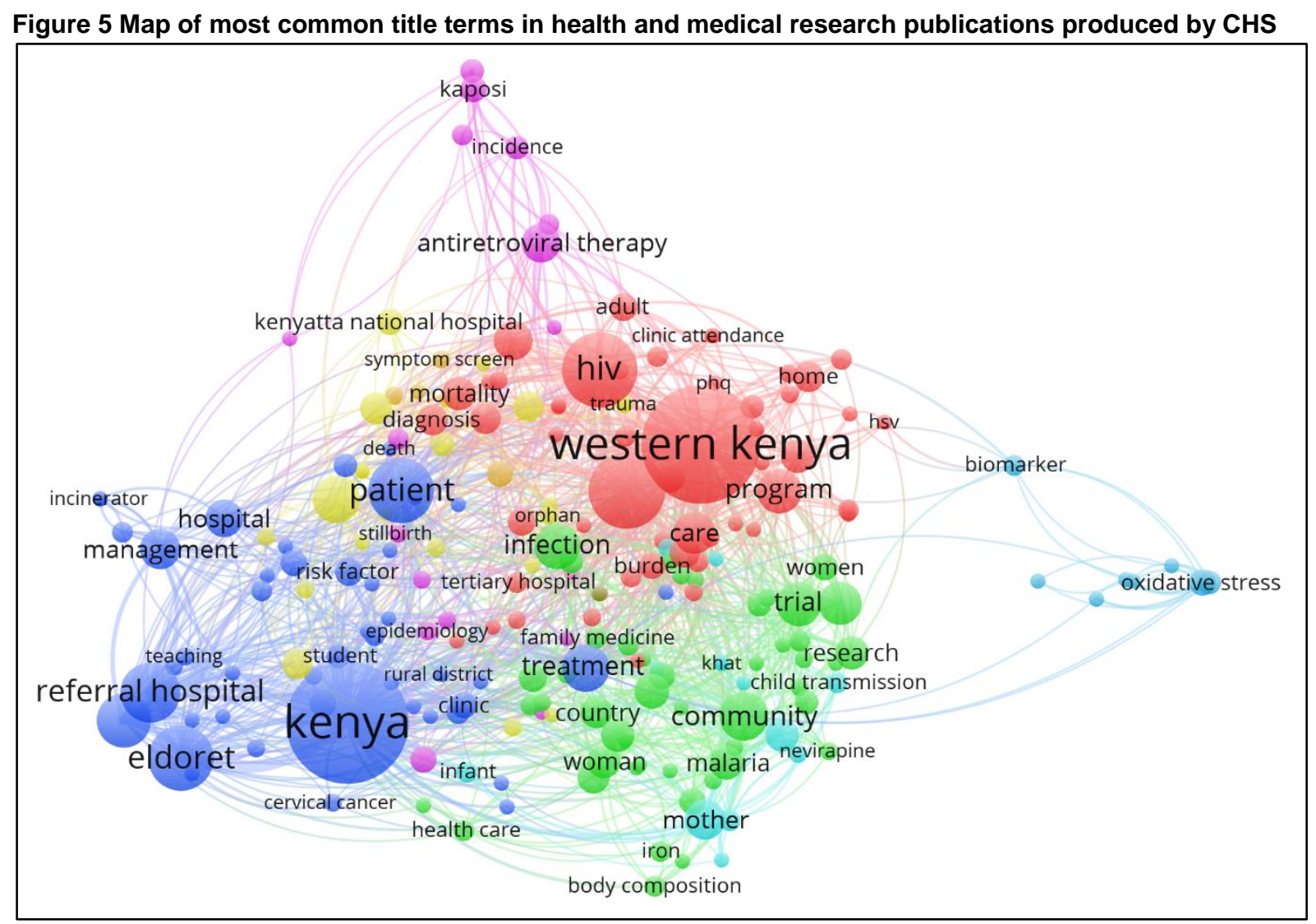

According to the findings of the study, the research areas that are prominent among academic staff at CHS are those using the terms 'Kenya' (117), 'western Kenya' (114), 'HIV' (sixty-five), 'child' (sixty-seven), 'Eldoret' (forty-eight), 'patient' (forty-eight), 'prevalence' (forty-seven), 'referral hospital' (forty), 'community' (forty), and 'infection' (thirty-nine). Other subject terms that featured in titles include 'malaria', 'tuberculosis', 'health care', 'risk factors', 'trauma', 'mortality', and others. Public health research seems to be attracting some attention from researchers. However, the most prominent topic of research was HIV/AIDS. HIV/AIDS has also emerged as a major concern in other African countries. Glover and Bowen (2004) conducted a study entitled 'Bibliometric analysis of research published in tropical medicine and international health 1996-2003' and noted, among other findings, that Africa has the highest representation, with 517 authored papers, the majority of which focus on HIVIADS. The authors attributed Africa's performance in terms of the research output to the "high burden of tropical diseases in the region in addition to the Sub-Saharan epidemic incidence of HIVIAIDS and tuberculosis" (Glover and Bowen 2004: 1328). In a study conducted in South Africa, Poreau (2015) observed that HIV was the chief field that emerged in the South African research articles published between 1975 and 2014 and as indexed in the Web of Science. The most common words in the titles in the current study, as aforementioned, reflect a similar pattern. Moi University is situated in the western region of Kenya and home to the only HIV/AIDS research facility in Africa, namely AMPATH. AMPATH is the centre of research on issues of HIV/AIDS and related topics. The Centre brings together both developing and established researchers from across several countries in the world, a situation that explains the collaboration patterns reflected in the map in Figure 4.

Researchers at the CHS collaborate with researchers from other countries, mostly a number of universities in the USA and Canada. This pattern follows the trend observed by Tijssen (2007) in a study on Africa's contribution to the worldwide research literature. Then, Tijssen (2007: 314) noted thus: "Kenya is the only one of the more highly developed African countries with a strong concentration of international research within medical and life sciences". Narvaez-Berthelemont et al. (2002: 229) have expressed similar sentiments by observing that "papers in international collaboration were overriding 
in biomedical research", among other subject categories. In fact, Narvaez-Berthelemont et al. (2002: 237) noted that international collaboration was on the rise across all African countries investigated in their study except in Sudan where international collaboration was on the decline. Narvaez-Berthelemont et al. (2002: 239) have attributed the reliance on international collaboration by researchers in African countries to colonial legacies and, more importantly, to the developing countries' "greater dependence on international co-authorship for mainstream publication". Foreign research funding is also a factor that promotes international collaboration in Africa. For instance, Tijssen (2007) has associated the heavy reliance on international collaboration in research to foreign research funding, which may dictate terms of collaboration, and the need of African researchers to publish their research in foreign-based journals. The role that AMPATH has played in shaping international collaboration cannot be overemphasised. AMPATH was created in 2001 as a joint partnership between Moi University and Indiana University as a comprehensive and effective HIV/AIDS control system in response to the deadliest pandemic in human history, and it is currently one of Africa's largest research consortia that has brought together a large network of researchers.

This study further found substantive amount of research collaboration among the academic staff of CHS within the university and outside the country. A number of collaboration clusters were identified associated with a number of research areas (see Figure 4 and Figure 5). The number of authors in some journal articles was as high as fifteen, which demonstrates the high level of collaboration in some topical areas. In medical research, there is always a need for collaboration due to the nature of research being undertaken - some research may require field and laboratory investigations at the same time. The high rate of co-authorship among the academics in CHS is healthy and a way of improving research in the area of health sciences. However, this kind of research is being discouraged as per the new, reviewed academic staff appointment and promotion policy of Moi University that has been harmonised with the Commission for University Education (CUE) in Kenya (CUE 2014). The points system in the new regulation in determining the suitability of one to be promoted to the next rank of academic level may turn out to be a deterrent to the progression of academic staff.

Research output from the CHS was published in 225 sources; sources that appear more frequently are produced regionally. The majority of research output from the CHS is published in journals from the region or those that bear the African name, with a sizeable number of journals from other regions publishing at least one journal article from the CHS. The number of journals publishing CHS output and the spread in terms of place of publication is a strong indication that the outputs from the CHS are globally accessible; hence they may have a global impact. Unlike the findings of the present study where research was largely published locally (journals published in African countries or bearing the name 'Africa/n'), Poreau's (2015) study revealed that South African public health research is mostly published in journals published outside Africa. Poreau (2015), nevertheless, noted that the South African Medical Journal (published in South Africa), published the highest number of articles on public health research in South Africa, thereby being the most preferred journal.

In conclusion, the authors believe that the availability of research funding through AMPATH as well as research collaboration in the $\mathrm{CHS}$ within Moi University and internationally have greatly contributed to the high number of research outputs among the academic staff of CHS. This finding agrees with those of Ocholla, Mostert \& Rotich (2016) whose study showed signs of high research productivity in the field of medicine. The indication is that, if the academic staff members access research funds and develop research clusters for collaborations, high research productivity will result. We therefore recommend that universities make research funds available to academic staff if they have to publish more journal articles to boost the reputation of the university in global rankings. Further research is however needed to ascertain the role that funding plays in research productivity.

Finally, given that the present study did not assess the citation characteristics of the medical and health research at the CHS so as to determine its impact, the authors strongly recommend a study to investigate the matter. Equally important is a study to benchmark this research against those of other countries in Africa, such as South Africa, which is said to have established research incentives in place (Pouris \& Richter 2000).

\section{References}

Aina, L.O. and Mabawonku, I. 1997. The literature of the information profession in Anglophone Africa: characteristics, trends and future. Journal of Information Science, 32(4): 321-326.

Aina, L.O. and Mooko N.P. 1999. Research and publication patterns in Library and Information Science. Information Development, 15(2): 114-119.

Alemna, A.A. 1996. The periodical literature of library and information in Africa: 1990-1995. International Information and Library Review, 28(2): 93-103.

Alemna, A.A. 2001. The periodical literature of library and information in Africa: 1996-2000. Information Development, 17(14): 257-261.

Alemna, A.A. and Badu, E. 1994. The nature and trends in research and journal literature in English speaking Africa. International Information \& Library Review, 26(1): 19-30.

Altbach, P.G. 2014. What counts for academic productivity in research universities? University World News. 18 July. [Online]. http://www.universityworldnews.com/article.php?story=20140715105656393 (21 November 2016).

Commission for University Education. 2014. Harmonized criteria and guidelines for appointment and promotion of academic staff in universities in Kenya. [Online].

http://repository.cue.or.ke:8080/xmlui/bitstream/handle/123456789/68/appointment_promotion_criteria_universities_2 014.pdf?sequence $=1$ \&isAllowed=y (15 December 2016).

Diodato, V. 1994. Dictionary of Bibliometrics. New York: Haworth. 
Garfield, E. 1996. Citation indexes for retrieval and research evaluation. Paper delivered at the Consensus Conference on the Theory and Practice of Research Assessment, Capri. 7 October 1996. [Online]. http://www.garfield.library.upenn.edu/papers/ciretreseval-capri2.pdf (7 January 2017).

Gauthier, E. 1998. Bibliometric analysis of scientific and technological research: a user's guide to the methodology. [Online]. http://publications.gc.ca/Collection/Statcan/88F0006X/88F0006XIE1998008.pdf (6 November 2016).

Glazel, W. 2002. Co-authorship patterns and trends in the sciences (1980-1998): a bibliometric study with implications for database indexing and search strategies. Library Trends, 50(3): 461-473.

Glover, S.W. and Bowen, S.L. 2004. Bibliometric analysis of research published in tropical medicine and international health: 1996-2003. Tropical Medicine and International Health, 9(12): 1327-1330.

Harzing, A. 2011. The public or perish book: your guide to effective and responsible citation analysis. Melbourne: Tarma Software Research.

Hertzel, D. 1987. Bibliometrics, history of the development of ideas in: statistical bibliography or bibliometrics? In Encyclopaedia of Library and Information Science. V. 42. A. Kent, Ed. 144-219.

Ingwersen P. and Jacobs D. 2002. South African research in selected scientific areas: status 1981-2000. Scientometrics, 59(3): 405-423.

Jacobs, D. 2002. Scientometrics of genetic research and development in South Africa, 1990-2001. In Progress in Library and Information Science in Southern Africa: proceedings of the second biennial DISSAnet conference. T. Bothma and A. Kaniki, Eds. Glenstantia: Infuse. 93-103.

Kadiri, J. 2001. Library literature in Ghana: 1950-1995. African Journal of Library, Archives and Information Science, $11(2): 158-166$.

Kenyatta, U.M. 2013. Speech by his Excellency, Uhuru Kenyatta, during the 2013 Jamhuri Day 50th Anniversary celebrations at Safaricom Stadium, Kasarani, Nairobi, on 12 December 2013. [Online]. https://www.scribd.com/document/191136965/President-Uhuru-Kenyatta-s-Speech-during-the-2013-Jamhuri-Day50th-Anniversary-Celebrations-at-Safaricom-Stadium-Kasarani-Nairobi (21 November 2016).

Kirigia, J.M. and Barry, S.P. 2008. Health challenges in Africa and the way forward. International Archives of Medicine, $1(1): 27$.

Lancaster, F.W. 1991. Bibliometric methods in assessing productivity and impact of research. Bangalore: Sarada Ranganathan Endowment for Library Science.

Lariviere, V. and Gingras, Y. 2010. The impact factor's Matthew Effect: a natural experiment in bibliometrics. Journal of the Association for Information Science and Technology, 61(2): 424-427.

Laudel, G. 2001. What do we measure by co-authorships? Proceedings of the 8th International Conference on Scientometrics and Informetrics. 16-20 July 2001. Sydney, Australia. 469-476.

Lwoga, E.T. and Sife A. 2014. Publication productivity and scholarly impact of academic libraries in Tanzania: a scientometric analysis. New Library World, 115(11/12): 527-541. DOI:10.1108/NLW-04-2014-0038.

Mabawonku, I. 2001. Trends in Library and Information Science research in Africa: 1991-2000. African Journal of Library, Archives and Information Science, 11(2): 79-88

Moi University 2012. Academic staff appointment and promotion policy. Office of DVC Academic, Research and Extension. (Unpublished).

Moi University 2015. Academic staff appointment and promotion policy. Office of DVC Academic, Research and Extension. (Unpublished).

Narvaez-Berthelemont, N., Russell, JM., Arvanitis, R., Waast, R and Gailard, J. 2002. Science in Africa: an overview of mainstream scientific output. Scientometrics, 54(2): 229-241.

Ndege, G.O. 2005. Kenya: independence to the present. In Encyclopedia of African history. K. Shillington, Ed. New York: Fitzroy Dearborn. 755-760.

Nicholas, D. and Ritchie, M. 1978. Literature and bibliometrics. London: Clive Bingley.

Ocholla, D.N. 2000. Research capacity in Library and Information Science in South Africa - an overview. Paper delivered at the 66th IFLA Council and General Conference. 13-18 August 2000. Jerusalem, Israel. [Online]. http://www.ifla.org/IV/ifla66/papers/054-127e.htm (4 April 2017)

Ocholla, D.N. 2001. An informetric study of the publication pattern in Library and Information Science in South Africa: 1993-2001. Proceedings of the 8th International Conference on Scientometrics and Informetrics. 16-20 July 2001, Sydney, Australia. 861-864.

Ocholla, D.N., Mostert, J. and Rotich D.C. 2016. Visibility of University of Zululand and Moi University researchers in Web of Science and Scopus from 2003 to 2013. African Journal of Libraries Archives \& Information Science, 26(1): 3-15.

Ocholla, D.N. and Ocholla, L. 2007. Research in library and information science in South Africa: an analysis of journals research output from 1993-2006. South African Journal of Libraries and Information Science, 73(2): 109-118.

Ocholla, D.N, Ocholla, L. and Onyancha, O.B. 2013. Insight into research publication output of academic librarians in Southern African public universities from 2002-2011. African Journal of Libraries Archives \& Information Science, 23(1): 5-22

Onyancha, O.B. 2007. LIS research in Africa: how much is it worth? A citation analysis of the literature, 1986-2006. South African Journal of Libraries and Information Science, 73(2): 95-108.

Onyancha, O.B. and Ocholla, D.N. 2009. Is HIV/AIDS in Africa distinct? What can we learn from an analysis of the literature? Scientometrics, 79(2): 277-296. 
Pagel, P.S. and Hudetz, J.A. 2011. An analysis of scholarly productivity in United States academic anaesthesiologists by citation bibliometrics. Anaesthesia, 66: 873-878. DOI:10.1111/j.1365-2044.2011.06860.x.

Poreau, B. 2015. Mapping South African public health research (1975-2014). South African Medical Journal, 105(1): 5255.

Pouris, A. and Richter, L. 2000. Investigation into state-funded research journals in South Africa. South African Journal of Science, 96: 98-104.

Sitienei, G. and Ocholla, D.N. 2010. A comparison of the research and publication patterns and output of academic librarians in Eastern and Southern Africa from 1990-2006: a preliminary study. South African Journal of Libraries \& Information Science, 76(1): 36-48.

Thomson Reuters. 2008. Using bibliometrics: a guide to evaluating research performance with citation data: white paper. [Online]. http://ip-science.thomsonreuters.com/m/pdfs/325133_thomson.pdf (7 January 2017).

Tijssen, R.J.W. 2007. Africa's contribution to the worldwide research literature: new analytical perspectives, trends, and performance indicators. Scientometrics, 71(2): 303-327.

Wallace, D. P. 1989. Bibliometrics and citation analysis. In Principles and Applications of Information Science for Library Professionals. J.N. Olsgaard, Ed. Chicago: American Library Association. 10-26. 